\title{
Antitumor activity of celastrol nanoparticles in a xenograft retinoblastoma tumor model
}

\author{
This article was published in the following Dove Press journal: \\ International Journal of Nanomedicine \\ 8 May 2012 \\ Number of times this article has been viewed
}

\section{Zhanrong $\mathrm{Li}^{1, *}$ \\ Xianghua $\mathrm{Wu}^{1, *}$ \\ jingguo $\mathrm{Li}^{2}$ \\ Lin Yao' \\ Limei Sun' \\ Yingying Shi' \\ Wenxin Zhang' \\ Jianxian Lin' \\ Dan Liang' \\ Yongping $\mathrm{Li}^{1}$}

'State Key Laboratory of Ophthalmology, Zhongshan Ophthalmic Center, ${ }^{2}$ School of Chemistry and Chemical Engineering, Sun Yat-Sen University, Guangzhou,

People's Republic of China

*These authors contributed equally to this work
Correspondence: Yongping Li or Dan Liang State Key Laboratory of Ophthalmology, Zhongshan Ophthalmic Center, Sun Yat-Sen University, 54 Xianlie South Road, Guangzhou, 510060, People's Republic of China

Tel +86 2087330492

Fax +86 2087334825

Email yongpingli1961@yahoo.com.cn; liangd2@mail.sysu.edu.cn
Background: Celastrol, a Chinese herbal medicine, has shown antitumor activity against various tumor cell lines. However, the effect of celastrol on retinoblastoma has not yet been analyzed. Additionally, the poor water solubility of celastrol restricts further therapeutic applications. The goal of this study was to evaluate the effect of celastrol nanoparticles (CNPs) on retinoblastoma and to investigate the potential mechanisms involved.

Methods: Celastrol-loaded poly(ethylene glycol)-block-poly( $\varepsilon$-caprolactone) nanopolymeric micelles were developed to improve the hydrophilicity of celastrol. The 2-(2-methoxy-4nitrophenyl)-3-(4-nitrophenyl)-5-(2,4-disulf-ophenyl)-2H tetrazolium monosodium salt (WST-8) assay was used to determine the inhibitory effect of CNPs on SO-Rb 50 cell proliferation in vitro. Immunofluorescence was used to evaluate the apoptotic effect of CNPs on nuclear morphology, and flow cytometry was used to quantify cellular apoptosis. The expression of

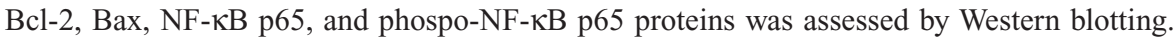
A human retinoblastoma xenograft model was used to evaluate the inhibitory effects of CNPs on retinoblastoma in NOD-SCID mice. Hematoxylin and eosin staining was used to assess the apoptotic effects of CNPs on retinoblastoma.

Results: CNPs inhibit the proliferation of SO-Rb 50 cells in a dose- and time-dependent manner with an $\mathrm{IC}_{50}$ of $17.733 \mu \mathrm{g} / \mathrm{mL}$ (celastrol-loading content: $7.36 \%$ ) after exposure to CNPs for 48 hours. CNPs induce apoptosis in SO-Rb 50 cells in a dose-dependent manner. The expres-

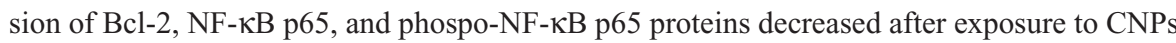
$54.4 \mu \mathrm{g} / \mathrm{mL}$ for 48 hours. Additionally, the $\mathrm{Bax} / \mathrm{Bcl}-2$ ratio increased, whereas the expression of Bax itself was not significantly altered. CNPs inhibit the growth of retinoblastoma and induce apoptosis in retinoblastoma cells in mice.

Conclusion: CNPs inhibit the growth of retinoblastoma in mouse xenograft model by inducing apoptosis in SO-Rb 50 cells, which may be related to the increased $\mathrm{Bax} / \mathrm{Bcl}-2$ ratio and the inhibition of NF- $\kappa$ B. CNPs may represent a potential alternative treatment for retinoblastoma.

Keywords: apoptosis, SO-Rb 50 cells, poly(ethylene glycol)-block-poly( $\varepsilon$-caprolactone), nanopolymeric micelles, celastrol nanoparticles

\section{Introduction}

Retinoblastoma is the most common childhood primary intraocular malignant tumor, with an incidence ranging from 1 in 15,000 to 1 in 18,000 live births. ${ }^{1,2}$ This represents approximately $4 \%$ of all pediatric malignancies, and approximately 5000 new cases of retinoblastoma are diagnosed around the world each year. Approximately $50 \%$ of children diagnosed with retinoblastoma survive their malignancy worldwide. ${ }^{3}$ Enucleation is the standard therapy for patients with advanced intraocular disease and is successful in treating intraocular retinoblastoma. ${ }^{4}$ Although enucleation can 
cure unilateral disease in approximately $95 \%$ of patients, it may result in vision loss and an unsatisfactory cosmetic appearance. ${ }^{5}$ Currently, drugs that induce apoptosis remain the main chemotherapeutic agents in medical oncology, ${ }^{6,7}$ and finding potential therapeutic drugs has been a major goal of retinoblastoma investigations.

Traditional Chinese herbal medicines provide a highly fertile ground for modern drug development. Trypterygium wilfordii Hook F, also known as the Thunder of God Vine, belongs to the Celastraceae family and has long been used in traditional Chinese medicine for the treatment of rheumatoid arthritis. ${ }^{8}$ Celastrol, a tripterine, is extracted from Trypterygium wilfordii Hook $\mathrm{F}$ and shows potential for the treatment of autoimmune diseases, ${ }^{9}$ chronic inflammation, ${ }^{10}$ and neurodegenerative diseases. ${ }^{11}$ Recent studies have demonstrated that celastrol can inhibit tumor cell proliferation and induce apoptosis. ${ }^{12,13}$ Further study showed that celastrol was a natural inhibitor of proteasome and NF- $\kappa$ B activity. ${ }^{14}$ The proteasome is responsible for degrading misfolded intracellular proteins and important cellular modulators, including the pro-apoptotic protein Bax. ${ }^{15}$ Activation of the NF- $\kappa$ B transcription factor has been connected with multiple aspects of oncogenesis, including the regulation of apoptosis, cell cycle progression, and cell migration. ${ }^{16}$ Inhibition of proteasome and/or NF- $\kappa$ B activity leads to cell death and is currently considered an attractive target for the treatment of cancer.

Although celastrol, as a natural inhibitor of the proteasome and NF- $\kappa \mathrm{B}$ activity, can induce apoptosis in a variety of tumor cell lines, including U937 cells, human prostate cancer cell lines, HL-60 cells, and human melanoma cells, ${ }^{12,14,17,18}$ the effects of celastrol on retinoblastoma are still not clear. Furthermore, the poor water solubility of celastrol limits its in vivo application. In a previous study, we found that poly(ethylene glycol)-block-poly ( $\varepsilon$-caprolactone) (PEG-b-PCL) micelles had promising potential to improve the hydrophilicity of celastrol and extend its release. ${ }^{19}$ Therefore, in this study, we investigated the effects of celastrol-loaded PEG-b-PCL nanopolymeric micelles on human retinoblastoma and explored the underlying mechanism of these effects.

\section{Materials and methods}

\section{Preparation of celastrol-loaded polymer micelles}

Chinese herbal celastrol (Figure 1A) was purchased from the Shanghai Institute of Materia Medica, Chinese Academy of Sciences, Shanghai, China. The preparation of celastrol-loaded polymer micelles was performed as previously described. ${ }^{19,20}$ Briefly, celastrol-loaded PEG-b-PCL micelles were prepared by dissolving PEG-b-PCL (2000:1000, $\mathrm{M}_{\mathrm{w}} / \mathrm{M}_{\mathrm{n}}=1.18$, JCS Biopolytech, Toronto, Canada; Figure 1B) (10 mg) and celastrol $(2 \mathrm{mg})$ in chloroform $(2 \mathrm{~mL})$, and adding the solution drop-wise to $\mathrm{ddH}_{2} \mathrm{O}(20 \mathrm{~mL})$ under ultrasonic agitation using a Type 60 Sonic Dismembrator (Fisher Scientific, Pittsburgh, PA). The organic solvent was then removed by vacuum distillation using a rotary evaporator to allow micelle formation. The samples were further concentrated and washed three times using a Millipore Centrifugal Filter Device (MW cutoff: 10,000 Da; Millipore, Billerica, MA) to remove free celastrol dissolved in the micelle solution, and then filtered with a syringe filter (pore size: $0.22 \mu \mathrm{m}$ ) to eliminate large polymer or celastrol aggregates. ${ }^{19}$

\section{In vitro release of celastrol from polymer micelles}

The celastrol-release study from polymer micelles in vitro was performed as previously described. ${ }^{19,20}$ Briefly, freezedried micelle samples (12 $\mathrm{mg}$ each) were resuspended in $3 \mathrm{~mL}$ of phosphate-buffered solution ( $\mathrm{pH}$ 7.4) or sodium acetate buffered solution ( $\mathrm{pH} 5.0)$ and then transferred into a dialysis bag (MW cutoff: 14,000 Da). The bag was placed into the same buffered solution $(50 \mathrm{~mL})$. The release study was performed at $37^{\circ} \mathrm{C}$ in a New Brunswick Scientific C24 incubator shaker (New Brunswick Scientific, Edison, NJ). At selected time intervals, buffered solution outside the dialysis bag was removed for reverse-phase high performance liquid chromatography columns (UltiMate 3000 HPLC System, Thermo Scientific, Sunnyvale, CA; $5 \mu \mathrm{m}, 4.6 \times 250 \mathrm{~mm}$ ) analysis and replaced with fresh buffer saline. Celastrol concentration was calculated based on the absorbance intensity at $425 \mathrm{~nm}$. The cumulative amount of drug released was calculated, and the percentages of drug released from micelles were plotted against time.

\section{Cell culture}

$\mathrm{SO}-\mathrm{Rb} 50$ cells, derived from a patient with human retinoblastoma, have been constantly preserved in our laboratory and were cultured in RPMI-1640 medium supplemented with 10\% fetal bovine serum (Gibco, Gaithersburg, MD), $100 \mathrm{U} / \mathrm{mL}$ penicillin, and $100 \mu \mathrm{g} / \mathrm{mL}$ streptomycin at $37^{\circ} \mathrm{C}$ in a $5 \% \mathrm{CO}_{2}$ atmosphere.

\section{In vitro SO-Rb 50 cell proliferation assay}

The inhibitory effects of celastrol nanoparticles (CNPs) on $\mathrm{SO}-\mathrm{Rb} 50$ cell proliferation were measured using the 
<smiles>CC1=C(O)C(=O)C=C2C1=CC=C1[C@@H]2CC[C@@]2(C)CC[C@@H](C(=O)O)CC[C@@]12C</smiles>

Celastrol
B<smiles>[Y][V]CCCCCC(=O)OCCOC</smiles>

$P E G_{x}-b-P C L_{y}$

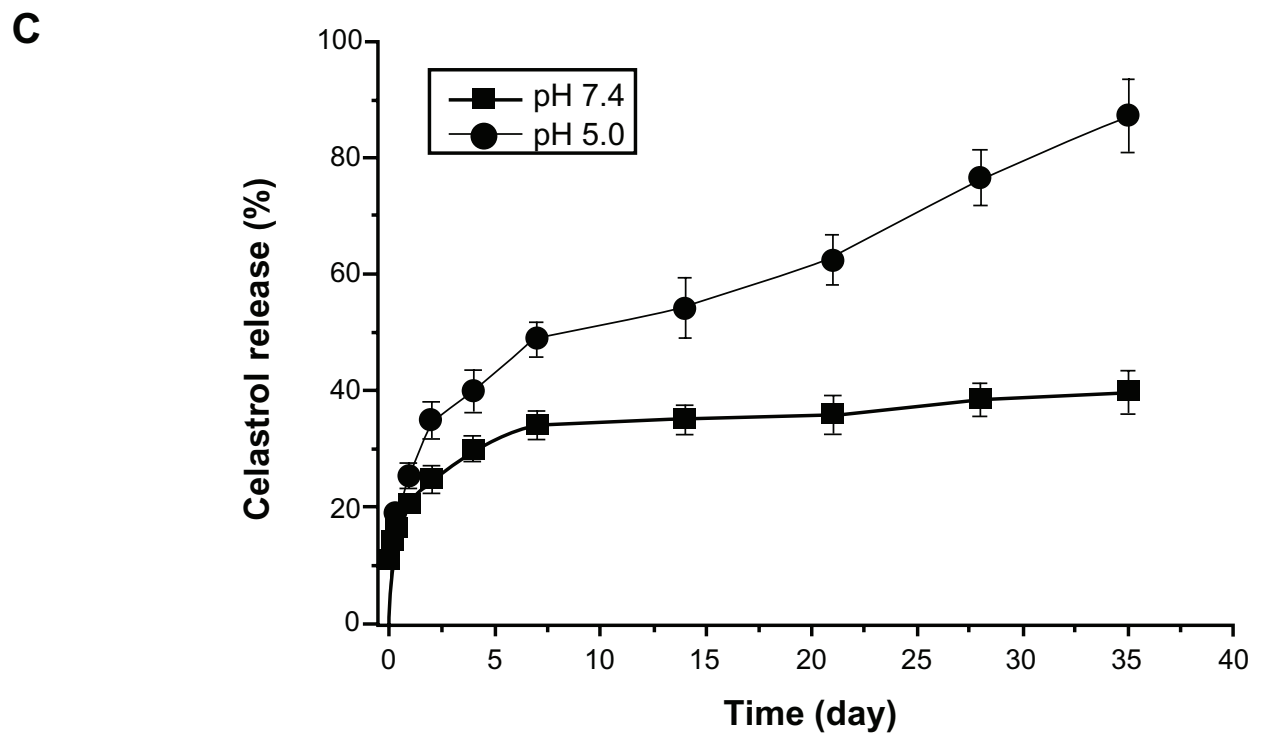

Figure I The chemical structures of (A) celastrol and (B) PEG-b-PCL nanopolymeric micelles. (C) In vitro drug release profiles of celastrol from PEG-b-PCL micelles (celastrol content: $7.36 \%$ ) in phosphate buffer solutions $(\mathrm{pH} 7.4)$ and sodium acetate buffered solution $\left(\mathrm{pH} 5.0\right.$ ) at $37^{\circ} \mathrm{C}$.

Notes: A typical two-phase-release profile contained a rapid release in the first stage followed by a sustained and slow release over a prolonged time up to several weeks in both solutions. Furthermore, celastrol release at pH 5.0 was significantly faster than that at $\mathrm{pH} 7.4$. The data are presented as the means \pm standard deviation $(\mathrm{n}=3$ ).

Abbreviation: PEG-b-PCL, poly(ethylene glycol)-block-poly(E-caprolactone).

2-(2-methoxy-4-nitrophenyl)-3-(4-nitrophenyl)-5-(2,4disulf-ophenyl)-2H tetrazolium monosodium salt (WST-8) reagent (Nacalai Tesque, Kyoto, Japan) according to the manufacturer's protocol. ${ }^{21} \mathrm{SO}-\mathrm{Rb} 50$ cells were plated at a density of $2 \times 10^{3}$ per well in triplicate in fresh medium for 24 hours. The CNPs were then diluted to appropriate concentrations and immediately applied to the cells. Dose-dependent inhibition was assessed by exposing cells to various concentrations of CNPs $(0-54.4 \mu \mathrm{g} / \mathrm{mL})$ and the same dosage of PEG-b-PCL micelles without celastrol, and culturing cells for an additional 48 hours. A time-dependent inhibition was performed by exposing cells to CNPs at a concentration of $27.2 \mu \mathrm{g} / \mathrm{mL}$ and or the same dose of blank micelles for 24,48 , and 72 hours. WST solution $(10 \mu \mathrm{L})$ was added to each well, and the cells were incubated for 4 hours at $37^{\circ} \mathrm{C}$. Cell viability was measured at $450 \mathrm{~nm}$. Variations in cell morphology were captured after treatment with CNPs for 48 hours. For comparison, the antiproliferation effect of free celastrol on $\mathrm{SO}-\mathrm{Rb} 50$ cells was also evaluated for celastrol dissolved in dimethyl sulfoxide $(0.2 \%, \mathrm{v} / \mathrm{v})$, concentrations of $0,0.25,0.5$, 1,2 , and $4 \mu \mathrm{g} / \mathrm{mL}$ for 48 hours and at a concentration of $2 \mu \mathrm{g} /$ $\mathrm{mL}$ for 24,48 , and 72 hours. The measurement protocol was followed according to the description above.

\section{Nuclear morphology}

$\mathrm{SO}-\mathrm{Rb} 50$ cells were allowed to grow on coverslips in a six-well culture plate (Corning, NY) for 24 hours. Next, the cells were treated with $54.4 \mu \mathrm{g} / \mathrm{mL}$ CNPs or blank micelles for 24 hours at $37^{\circ} \mathrm{C}$. Cells growing on glass coverslips were fixed with $4 \%$ paraformaldehyde for 10 minutes at room temperature. The fixed cells were washed twice with phosphate-buffered saline. Cells were then stained with Hoechst 33342 for 10 minutes. Nuclear morphology was observed under a fluorescence microscope. Apoptotic cells 
were identified by changes in nuclear morphology, such as chromatin condensation and fragmentation.

\section{Analysis of apoptosis by annexin V-FITC/propidium iodide staining}

Samples were labeled with annexin V-fluorescein isothiocyanate (FITC; BD Biosciences, San Diego, CA) and propidium iodide (PI) double staining according to the manufacturer's instructions, and then analyzed by flow cytometry. Briefly, after treatment with CNPs, cells were harvested and washed twice with ice-cold phosphate-buffered saline. Next, the cells were resuspended in $200 \mu \mathrm{L}$ of binding buffer $(10 \mathrm{mM}$ 4-(2-hydroxyethyl)-1-piperazineethanesulfonic acid $/ \mathrm{NaOH}$ $\mathrm{pH} 7.4,140 \mathrm{mM} \mathrm{NaCl}$, and $2.5 \mathrm{mM} \mathrm{CaCl}_{2}$ ) and $10 \mu \mathrm{L}$ of annexin V-FITC for 15 minutes in the dark. Then, $300 \mu \mathrm{L}$ of binding buffer and $5 \mu \mathrm{L}$ of PI were added to the samples for 15 minutes at room temperature in the dark, according to the manufacturer's instructions. Finally, the samples were analyzed using flow cytometry.

\section{Western blot analysis}

SO-Rb 50 cells were treated with $54.4 \mu \mathrm{g} / \mathrm{mL}$ CNPs or the same dose of blank micelles for 48 hours prior to deter-

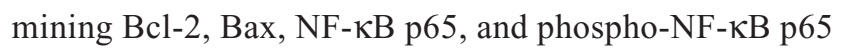
protein expression. The cells were collected, lysed, and the total protein concentration was quantified according to the manufacturer's instructions. An equal amount of each protein sample was loaded on sodium dodecyl sulfate gels and transferred to polyvinylidene difluoride membranes. The membranes were blocked with $5 \%$ nonfat dry milk at room temperature for 2 hours and incubated with anti-

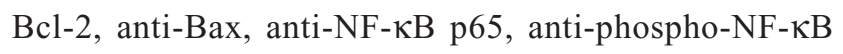
p65, and anti-glyceraldehyde 3-phosphate dehydrogenase primary antibodies (Cell Signaling Technology, Danvers, MA) overnight at $4^{\circ} \mathrm{C}$. Then, the membranes were washed and exposed to goat-anti-rabbit-IgG-HRP (Santa Cruz Biotechnology, Santa Cruz, CA) for 1 hour at room temperature, followed by imaging with a chemiluminescent substrate. The signal was assayed using the ChemiDoc XRs+(Bio-RAD, Hercules, CA) with enhanced chemiluminescence and analyzed using Image Lab (ECL). Glyceraldehyde 3-phosphate dehydrogenase was used as the loading control.

\section{Xenograft tumor model}

All animals in this study were used according to the Association for Research in Vision and Ophthalmology Statement ${ }^{22}$ in a protocol approved by the Zhongshan Ophthalmology
Center in Sun Yat-sen University (Guangzhou, China). Retinoblastoma mouse models were performed as previously described. ${ }^{23}$ Briefly, SO-Rb 50 tumor xenografts were established by subcutaneous injection of $5 \times 10^{7}$ cells into the right flanks of 5- to 6-week-old female NOD-SCID mice. When tumors reached a mean tumor volume of $100-200 \mathrm{~mm}^{3}$, as determined by the formula: volume $=$ length $\times$ width $^{2} \times 0.5$, the animals were randomly divided into two groups (five mice per group). The CNP group received intraperitoneal injections of CNPs (27.2 mg/kg/2 days); the control group was given the same dose of blank micelles by intraperitoneal injection. Tumor size was measured using vernier calipers every 4 days. In the tumor survival study, mice were euthanized according to our animal protocol, which instructed that the mice be euthanized within 1 week of the tumor size reaching $>1000 \mathrm{~mm}^{3}$.

\section{Histological analysis}

Tumor tissue was isolated, fixed in $10 \%$ formalin, and embedded in paraffin. Subsequently, $4-\mu \mathrm{m}$-thick sections of tumor tissue were cut and stained with hematoxylin and eosin solution. Tissue morphology was assessed by light microscopy.

\section{Statistical analysis}

All experiments were repeated three times. Quantitative variables are presented as the mean \pm standard deviation and analyzed using the SPSS (v16.0; SPSS, Chicago, IL). An independent sample $t$-test was performed to determine the significance of differences between the control and CNPtreated groups. Differences were considered statistically significant at $P<0.05$.

\section{Results}

The data for celastrol-loading content, measurements of dynamic light scattering, and transmission electron microscopy analysis of CNP diameters have been collected in our previous study. Our results showed that the celastrol-loading content is $7.36 \%$ and the mean diameter of CNPs with spherical shapes $48 \mathrm{~nm} .{ }^{19}$

\section{In vitro celastrol-release study}

The in vitro release behaviors of celastrol-loaded micelles in two different buffered solutions ( $\mathrm{pH} 7.4$ and 5.0) were studied (Figure 1C). In both solutions, a typical release profile featuring two phases was observed. That is, a relatively rapid release occurred in the first stage, followed by sustained and slow release over a prolonged time up to several weeks. 
In comparison with the release at $\mathrm{pH} 7.4$, celastrol release from micelles at $\mathrm{pH} 5.0$ is much faster.

\section{Inhibition of cell growth}

The inhibitory effect of CNPs on SO-Rb 50 cells was assessed using the WST- 8 assay, and the results are shown in Figure 2. SO-Rb 50 cells exposed to CNPs for 48 hours at concentrations ranging from $3.4-54.4 \mu \mathrm{g} / \mathrm{mL}$ showed decreased cell viability as a function of concentration. Cell viability was approximately $30 \%$ relative to the control cells at a concentration of $27.2 \mu \mathrm{g} / \mathrm{mL}$ CNPs. Changes in the morphology of cells revealed that increasing the amount of CNPs decreased the number and size of SO-RB 50 cells (Figure 2A). Cell viability was determined after treatment with either blank micelles or CNPs at different concentrations (Figure 2B). CNPs had a dose-dependent inhibitory effect on proliferation with an $\mathrm{IC}_{50}$ value of $17.733 \mu \mathrm{g} / \mathrm{mL}$ after exposure to CNPs for 48 hours. The $\mathrm{IC}_{50}$ of free celastrol on SO-Rb 50 cells was $0.843 \mu \mathrm{g} / \mathrm{mL}$. Figure $2 \mathrm{C}$ demonstrates a time-dependent decrease in the cell viability of SO-Rb 50 cells. CNP-treated cells $(27.2 \mu \mathrm{g} / \mathrm{mL})$ had a viability of $31.94 \%$ compared to controls following exposure for 48 hours. Free celastrol revealed an enhanced inhibitory effect on SO-Rb 50 cells at different time points (Figure 2C). Therefore, it can be concluded that the CNPs inhibited proliferation of human $\mathrm{SO}-\mathrm{Rb} 50$ cell growth in both a dose- and time-dependent manner.

\section{Apoptosis}

To investigate the effect of CNPs on apoptosis, we stained SO-Rb 50 cells with Hoechst 33342 after 24 hours of exposure to $54.4 \mu \mathrm{g} / \mathrm{mL} \mathrm{CNPs}$, and subsequently, examined changes in cell morphology using a fluorescence microscope. Figure 3 depicts the significant morphological changes in nuclear chromatin after treatment with CNPs for 24 hours. Untreated cells contain round nuclei with homogeneous chromatin (Figure 3A), whereas the nuclei of cells treated with CNPs display classic morphological characteristic of apoptosis, including a reduction in nuclear size, chromatin condensation, and DNA fragmentation (Figure 3B).
A

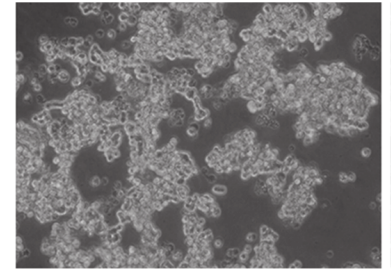

$0 \mu \mathrm{g} / \mathrm{mL}$

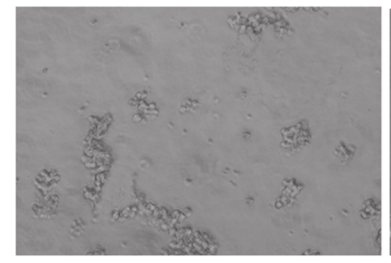

$13.6 \mu \mathrm{g} / \mathrm{ML}$

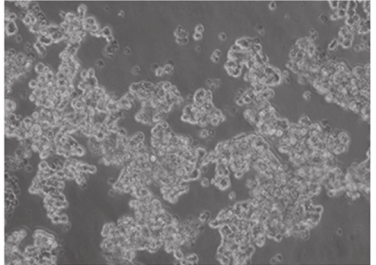

$3.4 \mu \mathrm{g} / \mathrm{mL}$

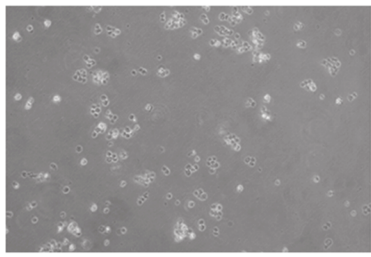

$27.2 \mu \mathrm{g} / \mathrm{ML}$

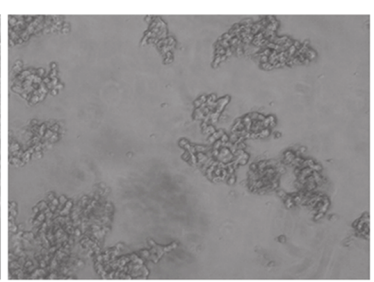

$6.8 \mu \mathrm{g} / \mathrm{mL}$

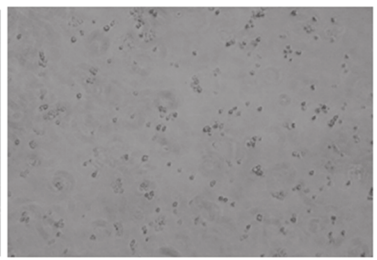

$54.4 \mu \mathrm{g} / \mathrm{ML}$
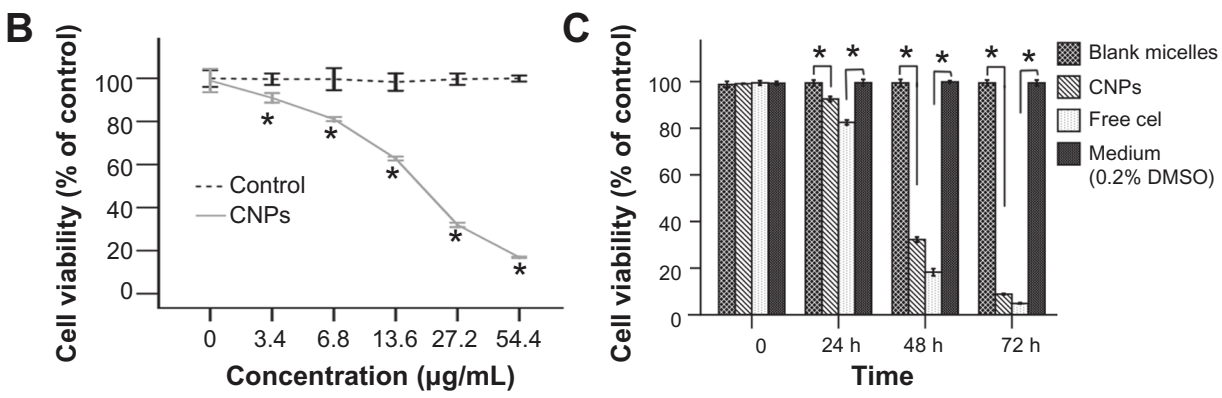

Figure 2 CNPs inhibit the proliferation of human SO-Rb 50 cells in vitro. (A) Morphological variations of SO-Rb 50 cells treated with 0-54.4 $\mu$ g/mL CNPs for 48 hours (100 $\times$ magnification). Increasing the amount of CNPs decreased the number and size of SO-RB 50 cells. (B) The dose-dependent effect of CNPs on cell viability. SO-Rb 50 cells were treated with $0-54.4 \mu \mathrm{g} / \mathrm{mL}$ CNPs for 48 hours. The $I_{50}$ is $17.733 \mu \mathrm{g} / \mathrm{mL}$ when exposed to CNPs for 48 hours. (C) The time-dependent effect of CNPs on the cell viability. SO-Rb 50 cells were, respectively, treated with $27.2 \mu \mathrm{g} / \mathrm{mL}$ CNPs and $2 \mu \mathrm{g} / \mathrm{mL}$ free celastrol dissolved in $0.2 \%$ (v/v) DMSO for $0,24,48$, and 72 hours.

Notes: The medium ( $0.2 \%$ DMSO) and blank micelles without celastrol showed a cell viability of greater than $95 \%$. The results are reported as the means \pm standard deviation ( $\mathrm{n}=3$ ) which were performed in triplicate. Statistical significance was based on the difference compared to control cells treated with medium $(* \mathrm{P}<0.0 \mathrm{I}$, error bar, $95 \% \mathrm{Cl})$. Abbreviations: $\mathrm{Cl}$, confidence interval; CNPs, celastrol nanoparticles; Cel, celastrol; DMSO, dimethyl sulfoxide. 

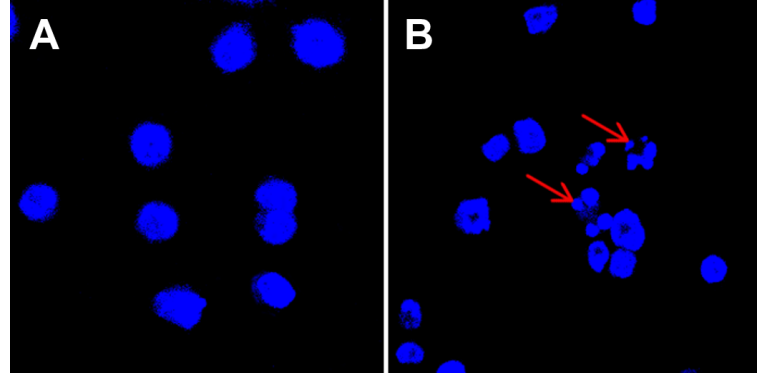

Figure 3 CNPs induce apoptosis in SO-Rb 50 cells. Fluorescence micrographs of SO-Rb 50 cells are shown after exposure to $(\mathbf{A})$ blank micelles and (B) CNPs at $54.4 \mu \mathrm{g} / \mathrm{mL}$ for 24 hours ( $400 \times$ magnification).

Notes: Cells were stained with Hoechst 33342 to visualize nuclear morphology. Blank micelle-treated SO-Rb 50 cells have round nuclei with homogeneous chromatin. The cells treated with CNPs are characterized by chromatin condensation, a reduction of nuclear size, and nuclear fragmentation (red arrows show nuclear fragmentation).

Abbreviation: CNPs, celastrol nanoparticles.

To quantify cellular apoptosis, the SO-Rb 50 cells were treated with CNPs at concentrations of $0,27.2,54.4$, and $108.8 \mu \mathrm{g} / \mathrm{mL}$ for 24 hours. The cells were subsequently co-stained with annexin V-FITC/PI and analyzed by flow cytometry. Representative dot plots of annexin V-FITC/PI staining of SO-Rb 50 cells are shown in Figure 4A, and the percentage of apoptotic cells relative to CNP concentration are shown in Figure 4B. Only a small number of apoptotic cells were detected in 0 and $27.2 \mu \mathrm{g} / \mathrm{mL} \mathrm{CNP}$-treated groups. However, a significant increase in the number of apoptotic cells could be detected in the 54.4 and $108.8 \mu \mathrm{g} / \mathrm{mL}$ CNPtreated groups. The number of SO-Rb 50 cells undergoing early- and late-stage apoptosis were $6.7 \%$ and $24.4 \%$, respectively, following incubation with $54.4 \mu \mathrm{g} / \mathrm{mL} \mathrm{CNPs}$ for 24 hours. The corresponding numbers in the $108.8 \mu \mathrm{g} / \mathrm{mL}$ CNP treatment group were $6.3 \%$ and $48.4 \%$, respectively. This demonstrates that CNPs induced apoptosis, especially late-stage apoptosis, in a dose-dependent manner.

\section{Effect on apoptotic proteins}

We determined the expression levels of Bcl-2, Bax, NF- $\kappa \mathrm{B}$ p65, and phospho-NF- $\mathrm{B}$ p65 to understand the effect of CNPs on apoptosis-related proteins in SO-Rb 50 cells. After 48 hours of exposure to $54.4 \mu \mathrm{g} / \mathrm{mL} \mathrm{CNPs}$, the levels

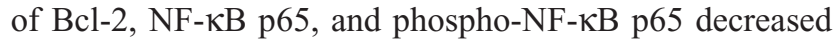
significantly (Figure 5A). Although the expression of Bax showed little change, the ratio of $\mathrm{Bax} / \mathrm{Bcl}-2$ increased significantly (Figure 5B).

\section{Antitumor effect in vivo}

Following the investigation of apoptosis induction in SO-Rb 50 cells in vitro, the antitumor effect of celastrol nanoparticles

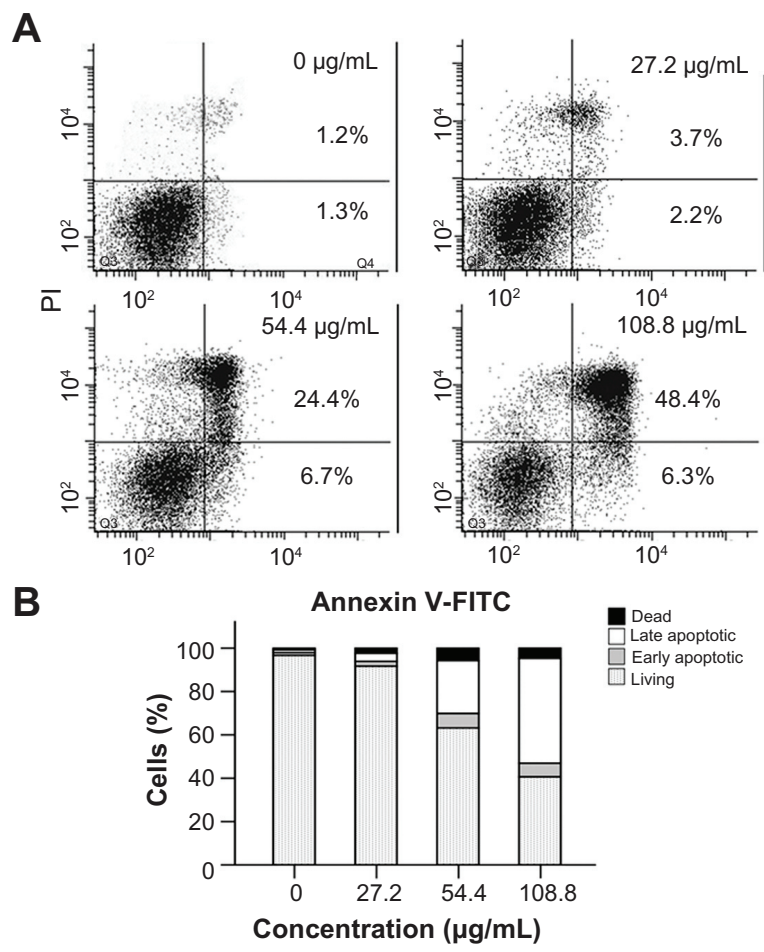

Figure 4 Annexin V-FITC/PI double staining analysis of apoptosis in SO-Rb 50 cells at 24 hours post-treatment. (A) Dot plot for flow cytometric analysis of apoptotic cells. Living cells tested negative for both annexin V-FITC and PI. Populations testing annexin $\mathrm{V}$ positive/PI negative were classified as early-stage apoptotic cells, and double-positive cells were classified as late-stage apoptotic cells. (B) Bar graph quantifying the percentage of dead, living, early-stage apoptotic, and late-stage apoptotic cells according to treatment.

Note: The values shown are the mean of three independent experiments.

Abbreviations: FITC, fluorescein isothiocyanate; PI, propidium iodide; CNPs, celastrol nanoparticles.

was evaluated in vivo. We established a retinoblastoma xenograft model by injecting SO-Rb 50 cells into NOD/ SCID mice. Administration of $27.2 \mathrm{mg} / \mathrm{kg}$ CNPs every other day for 16 days substantially suppressed tumor volume (Figure 6A) and reduced tumor weight (Figure 6C). The average tumor volume in the control mice increased from $107.08 \pm 8.60 \mathrm{~mm}^{3}$ to $1091.41 \pm 75.74 \mathrm{~mm}^{3}$ after 16 days, whereas the average tumor volume in the CNP-treated mice decreased from $112.36 \pm 7.52 \mathrm{~mm}^{3}$ to $76.11 \pm 6.14 \mathrm{~mm}^{3}$ (Figure 6A). Additionally, the average tumor weight in the control group was $623.20 \pm 108.85 \mathrm{mg}$, whereas the average tumor weight in the CNP-treated group was only $58.80 \pm 18.13 \mathrm{mg}$ (Figure 6C), indicating a significant inhibition of tumor growth. However, the same dose of CNPs had no significant effect on the body weight of mice compared to the control group (Figure 6B).

\section{Histological examination}

In control tumor tissue sections, the retinoblastoma cell nuclei were large with prominent nucleoli, and only a few cells 

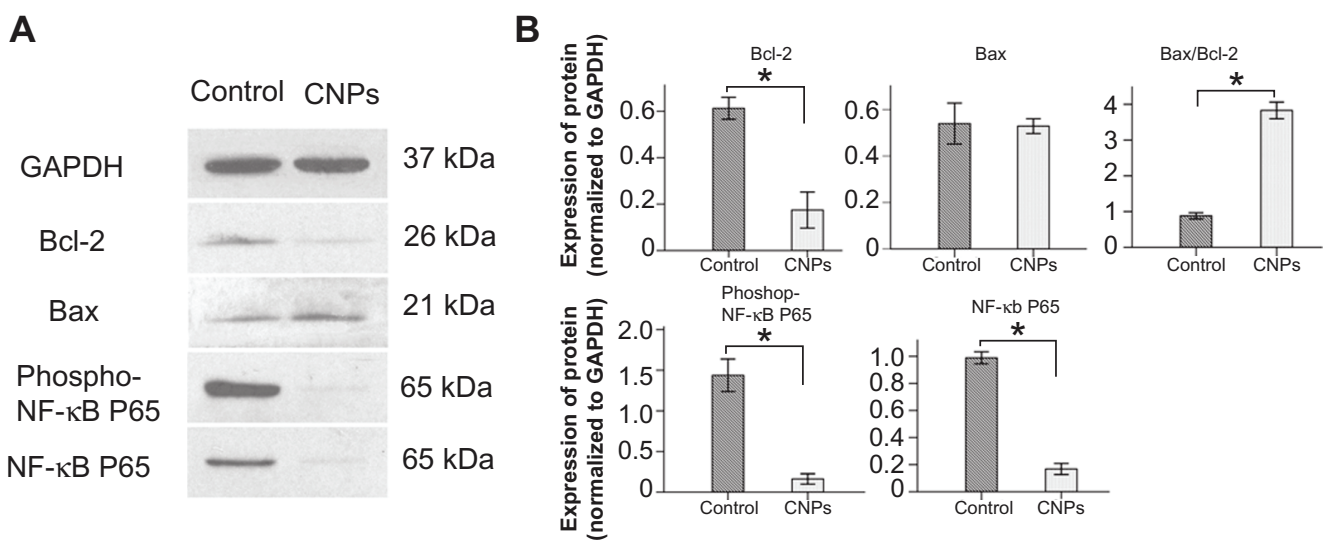

Figure 5 Effect of CNPs on the expression level of Bcl-2, Bax, NF- $\kappa B$ p65, and phospho-NF- $\mathrm{BB}$ p65. The SO-Rb 50 cells were incubated with blank micelles or CNPs $(54.4 \mu \mathrm{g} / \mathrm{mL})$ for 48 hours. Western blot analyses were performed with antibodies against Bcl-2, Bax, NF- $\mathrm{KB}$ p65, and phospho-NF- $\kappa \mathrm{B}$ p65.

Notes: GAPDH expression is shown as a loading control. This figure is representative of three independent experiments. The data are presented as means \pm standard deviation. Statistical significance is based on the difference when compared with blank micelle-treated cells $(* P<0.00 \mathrm{I})$.

Abbreviations: CNPs, celastrol nanoparticles; GAPDH, glyceraldehyde 3-phosphate dehydrogenase.

showed a reduction in nuclear size with deeply stained nuclei and condensed cytoplasm (Figure 7A). In contrast, a greater number of cells had hyperchromatic nuclei and a reduction in nuclear size in the CNP-treated group (Figure 7B).

\section{Discussion}

In this study, we demonstrate that CNPs can suppress the growth of human retinoblastoma in a xenograft mouse model.
One of the major mechanisms through which CNPs mediate their effects against retinoblastoma is by inducing apoptosis in tumor cells.

Celastrol can inhibit the proliferation of multiple tumor cell lines in vivo and in vitro through the induction of apoptosis in tumor cells and the suppression of tumor angiogenesis. ${ }^{13,14,24}$ However, the effect of celastrol on retinoblastoma has not previously been addressed. Additionally,
A

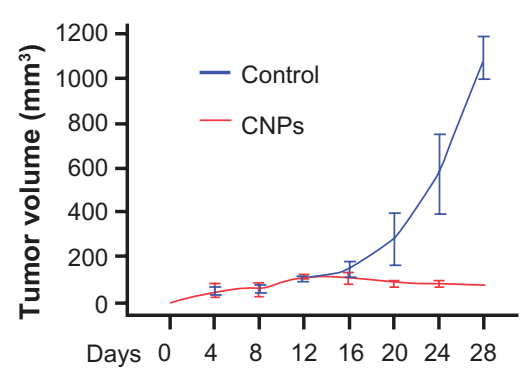

C

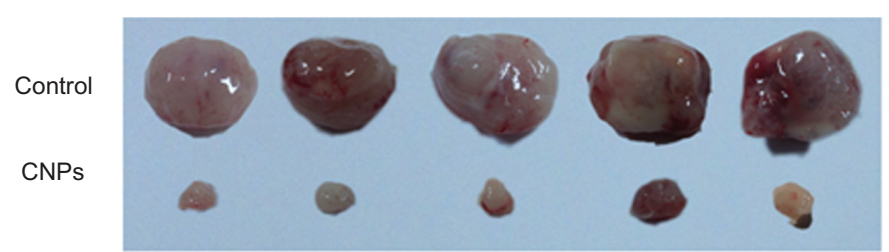

B
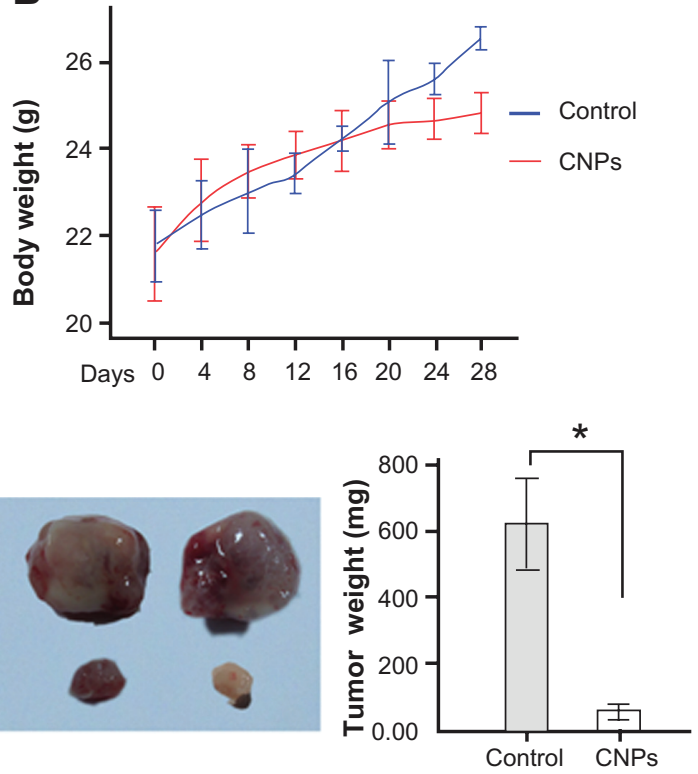

Figure 6 CNPs suppress retinoblastoma growth in a xenograft mouse model. SO-Rb 50 cells were subcutaneously injected into 6 -week-old NOD SCID mice $\left(5 \times 10^{7}\right.$ per mouse). The mice were administrated CNPs or blank micelles $\left(27.2 \mathrm{mg} / \mathrm{kg} / 2\right.$ days) by intraperitoneal injections after solid tumors grew to $100 \mathrm{~mm}{ }^{3}$. (A) CNPs inhibit tumor growth as measured by tumor volume. (B) As demonstrated by the change in body weight, CNPs had little toxicity in mice at the doses tested. (C) Solid tumors in mice treated with CNPs were significantly smaller than those in control mice.

Notes: $* P<0.00$ I versus control. Error bars: $95 \% \mathrm{Cl}$.

Abbreviation: CNPs, celastrol nanoparticles. 


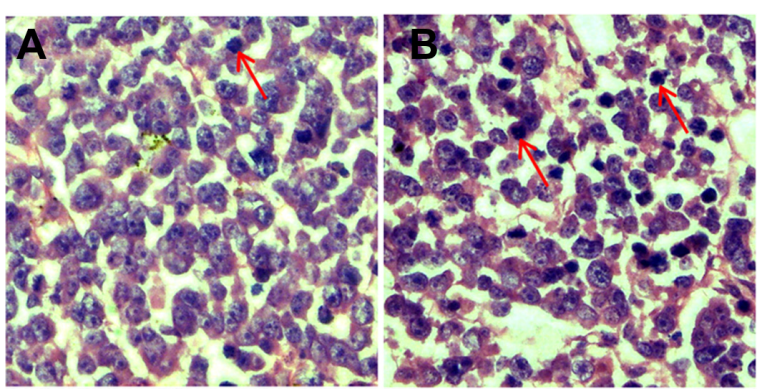

Figure 7 CNPs induce apoptosis in retinoblastoma cells. Retinoblastoma induced by inoculation with SO-Rb 50 cells were treated with blank micelles and CNPs at $27.2 \mathrm{mg} / \mathrm{kg}$ every other day for 3 weeks. Retinoblastoma tissue sections of (A) control and (B) CNP groups were stained with hematoxylin and eosin.

Note: A greater number of cells showed a reduction in nuclear size, deeply stained nuclei, and condensed cytoplasm in the CNP group (red arrows show hyperchromatic nuclei)

Abbreviation: CNPs, celastrol nanoparticles.

the poor water solubility of celastrol is an obstacle to further therapeutic applications. PEG-b-PCL polymeric micelles have been widely investigated in medical research due to their ability to increase hydrophilicity and extend the release of a drug. ${ }^{25-27}$ Drug-loaded polymeric micelles target tumor tissues through enhanced permeation and retention of the vasculature surrounding tumors. ${ }^{28}$ Therefore, nanopolymeric micelles have been considered as an important and attractive class of drug carriers. Previously, it has been reported that PEG-b-PCL micelles loaded with anticancer drugs could significantly improve the efficacy of chemotherapeutic agents. ${ }^{29}$ Therefore, we chose PEG-b-PCL as the celastrol delivery carrier to further study the effects of CNPs on retinoblastoma in a xenograft mouse model. In a previous study, we demonstrated that PEG-b-PCL could significantly improve the water solubility of celastrol. ${ }^{19}$ We found a typical two-phase-release profile of celastrol release from micelles. Additionally, faster release of celastrol in acidic conditions was also observed, consistent with previous reports. ${ }^{27}$ This $\mathrm{pH}$-dependent releasing behavior is of particular interest in achieving the tumor-targeted celastrol delivery with micelles. ${ }^{30}$ Micellar particles are generally internalized inside the cells by endocytosis; therefore, faster release inside the lysosome of tumor cells (at approximately pH 5.0) may occur due to the decreased $\mathrm{pH}$ values. ${ }^{31}$

Celastrol is a component of several herbal medicines that have been known to have antitumor activity. Celastrol itself has antiproliferative activity on different tumor cell lines. ${ }^{32}$ In the present study, an in vitro WST assay demonstrated that CNPs inhibit the proliferation of SO-Rb 50 cells in a dose-dependent and time-dependent manner, with an $\mathrm{IC}_{50}$ value of $17.733 \mu \mathrm{g} / \mathrm{mL}$ (celastrol-loading content: $7.36 \%$, concentration of celastrol: $1.305 \mu \mathrm{g} / \mathrm{mL}$ ). Free celastrol had an $\mathrm{IC}_{50}$ value of $0.843 \mu \mathrm{g} / \mathrm{mL}$ and also showed an enhanced inhibitory effect on SO-Rb 50 cells at different time points. The lower potency of micelle-delivered celastrol may be due to a delayed celastrol release from micelles, which is consistent with our study of in vitro celastrol release study.

To further analyze CNP-induced cytotoxicity, we investigated the apoptotic effects of CNPs on SO-Rb 50 cells. Apoptosis is an important method of maintaining the balance between cell division and cell death, ${ }^{33}$ and the induction of apoptosis in tumor cells is an important focus of antitumor drug discovery. ${ }^{34}$ This study demonstrates that morphological changes occur in the nucleus of SO-Rb 50 cells following treatment with CNPs for 24 hours. Flow analysis revealed a dose-dependent increase in apoptosis in CNP-treated SO-Rb 50 cells. In vivo, CNPs significantly inhibited the growth of retinoblastoma in a xenograft tumor model in NOD-SCID mice. Additionally, hematoxylin and eosin staining showed that CNPs induced apoptosis in the retinoblastoma cells.

Bcl-2 family members include both anti-apoptotic proteins, such as Bcl-2, and pro-apoptotic proteins, such as Bax. ${ }^{35}$ These proteins are essential in regulating the mitochondrial apoptotic pathway. ${ }^{36}$ Overexpression of Bax enhances cell apoptosis, whereas $\mathrm{Bcl}-2$ inhibits this process. ${ }^{37} \mathrm{~A}$ change in the $\mathrm{Bax} / \mathrm{Bcl}-2$ ratio could lead to cell death. ${ }^{38}$ In the current study, CNPs downregulated the expression of Bcl-2, and thereby increased the Bax/Bcl-2 ratio in SO-Rb 50 cells. This suggests that CNPs could change the expression of apoptotic proteins and may trigger apoptosis through a mitochondriadependent pathway in SO-Rb 50 cells.

$\mathrm{NF}-\kappa \mathrm{B}$ is a transcription factor that is strongly related to the inhibition of apoptosis, in addition to contributing to tumor growth, metastasis, and chemoresistance. ${ }^{35}$ Overexpression of NF- $\mathrm{kB}$ factors has been shown to block apoptosis. ${ }^{39}$ In human retinoblastoma cells, the transcriptional activity of NF- $\mathrm{kB}$ is necessary for survival. ${ }^{40} \mathrm{~A}$ recent study suggested that the expression of p65 and c-Rel proteins, $\mathrm{NF}-\mathrm{KB}$ transcription factor family members, represented a reliable marker for human retinoblastoma. ${ }^{41}$ Celastrol has previously been considered a natural NF- $\mathrm{KB}$ inhibitor. ${ }^{13}$ In this study, SO-Rb 50 cells expressed higher levels of NF- $\mathrm{KB}$ p65 and phospho-NF- $\mathrm{kB}$ p65, consistent with previous studies. ${ }^{40}$ In contrast, the expression of NF-kB p65 and phospho-NF- $\kappa \mathrm{B}$ p65 was decreased in the CNP-treated group. Celastrol displayed potent suppression of NF- $\kappa B$ p 65 activity in human retinoblastoma cells. This may be one of the mechanisms through which CNPs induce apoptosis in $\mathrm{SO}-\mathrm{Rb} 50$ cells. 


\section{Conclusion}

In this study, we demonstrate that CNPs significantly inhibit the proliferation of human retinoblastoma $\mathrm{SO}-\mathrm{Rb} 50$ cells in a dose- and time-dependent manner. CNPs inhibit retinoblastoma growth in a xenograft mouse model by inducing apoptosis in SO-Rb 50 cells, which may be related to an increase in the $\mathrm{Bax} / \mathrm{Bcl}-2$ ratio and inhibition of $\mathrm{NF}-\kappa \mathrm{B}$. CNPs may represent a potential alternative treatment for retinoblastoma.

\section{Acknowledgments}

The authors received financial support from the Doctoral Program Foundation of Institutions of Higher Education of China (20090171110084), and Guangdong Provincial Department University-Industry Cooperation Projects (2010B090400415). We thank Professors Chuanbin Wu and Jinyuan Nie from the School of Pharmaceutical Sciences for their technical support with the high-performance liquid chromatographical analysis.

\section{Disclosure}

There are no conflicts of interest to report.

\section{References}

1. Devesa SS. The incidence of retinoblastoma. Am J Ophthalmol. 1975;80(2):263-265.

2. Bishop JO, Madson EC. Retinoblastoma. Review of the current status. Surv Ophthalmol. 1975;19(6):342-366.

3. Shields CL, Shields JA. Diagnosis and management of retinoblastoma. Cancer Control. 2004;11(5):317-327.

4. Abramson DH, Schefler AC. Update on retinoblastoma. Retina. 2004;24(6):828-848

5. Byrne J, Fears TR, Whitney C, Parry DM. Survival after retinoblastoma: long-term consequences and family history of cancer. Med Pediatr Oncol. 1995;24(3):160-165.

6. Elison JR, Cobrinik D, Claros N, Abramson DH, Lee TC. Small molecule inhibition of HDM2 leads to p53-mediated cell death in retinoblastoma cells. Arch Ophthalmol. 2006;124(9):1269-1275.

7. Zhang H, Li B, Bai SW, Wang HJ. Constitutively active Akt contributes to vincristine resistance in human retinoblastoma cells. Cancer Invest. 2010;28(2):156-165.

8. Tao X, Cush JJ, Garret M, Lipsky PE. A phase I study of ethyl acetate extract of the chinese antirheumatic herb Tripterygium wilfordii hook F in rheumatoid arthritis. J Rheumatol. 2001;28(10):2160-2167.

9. Li H, Zhang YY, Tan HW, Jia YF, Li D. Therapeutic effect of tripterine on adjuvant arthritis in rats. J Ethnopharmacol. 2008;118(3):479-484.

10. Pinna GF, Fiorucci M, Reimund JM, Taquet N, Arondel Y, Muller CD. Celastrol inhibits pro-inflammatory cytokine secretion in Crohn's disease biopsies. Biochem Biophys Res Commun. 2004;322(3):778-786.

11. Allison AC, Cacabelos R, Lombardi VR, Alvarez XA, Vigo C. Celastrol, a potent antioxidant and anti-inflammatory drug, as a possible treatment for Alzheimer's disease. Prog Neuropsychopharmacol Biol Psychiatry. 2001;25(7):1341-1357.

12. Wang XN, Wu Q, Yang X, Zhang LS, Wu YP, Lu C. Effects of Celastrol on growth inhibition of U937 leukemia cells through the regulation of the Notch1/NF-kappaB signaling pathway in vitro. Chin J Cancer 2010;29(4):385-390.
13. Zhou LL, Lin ZX, Fung KP, et al. Celastrol-induced apoptosis in human $\mathrm{HaCaT}$ keratinocytes involves the inhibition of NF-kappaB activity. Eur J Pharmacol. 2011.

14. Yang H, Chen D, Cui QC, Yuan X, Dou QP. Celastrol, a triterpene extracted from the Chinese "Thunder of God Vine," is a potent proteasome inhibitor and suppresses human prostate cancer growth in nude mice. Cancer Res. 2006;66(9):4758-4765.

15. Nunes CT, Miners KL, Dolton G, et al. A novel tumor antigen derived from enhanced degradation of bax protein in human cancers. Cancer Res. 2011;71(16):5435-5444.

16. Baldwin AS. Control of oncogenesis and cancer therapy resistance by the transcription factor NF-kappaB. J Clin Invest. 2001;107(3):241-246.

17. Nagase M, Oto J, Sugiyama S, Yube K, Takaishi Y, Sakato N. Apoptosis induction in HL-60 cells and inhibition of topoisomerase II by triterpene celastrol. Biosci Biotechnol Biochem. 2003;67(9):1883-1887.

18. Abbas S, Bhoumik A, Dahl R, et al. Preclinical studies of celastrol and acetyl isogambogic acid in melanoma. Clin Cancer Res. 2007;13(22 Pt 1): 6769-6778.

19. Li Z, Yao L, Li J, et al. Celastrol nanoparticles inhibit corneal neovascularization induced by suturing in rats. Int $J$ Nanomedicine. 2012;7:1163-1173.

20. Cao N, Cheng D, Zou S, Ai H, Gao J, Shuai X. The synergistic effect of hierarchical assemblies of siRNA and chemotherapeutic drugs co-delivered into hepatic cancer cells. Biomaterials. 2011;32(8): 2222-2232.

21. Tamura S, Hosoi H, Kuwahara Y, et al. Induction of apoptosis by an inhibitor of EGFR in neuroblastoma cells. Biochem Biophys Res Commun. 2007;358(1):226-232.

22. The Association for Research in Vision and Ophthalmology. Rockville: 2010 ARVO Statement for the Use of Animals in Ophthalmic and Vision Research. Available from: http://www.arvo.org/eweb/dynamicpage.asp $\mathrm{x}$ ?site $=$ arvo2\&webcode=AnimalsResearch. Accessed March 13, 2012

23. Song X, Zhou Y, Jia R, et al. Inhibition of retinoblastoma in vitro and in vivo with conditionally replicating oncolytic adenovirus H101. Invest Ophthalmol Vis Sci. 2010;51(5):2626-2635.

24. Pang X, Yi Z, Zhang J, et al. Celastrol suppresses angiogenesismediated tumor growth through inhibition of AKT/mammalian target of rapamycin pathway. Cancer Res. 2010;70(5):1951-1959.

25. Mikhail AS, Allen C. Poly(ethylene glycol)-b-poly(epsilon-caprolactone) micelles containing chemically conjugated and physically entrapped docetaxel: synthesis, characterization, and the influence of the drug on micelle morphology. Biomacromolecules. 2010;11(5):1273-1280.

26. Yanez JA, Forrest ML, Ohgami Y, Kwon GS, Davies NM. Pharmacometrics and delivery of novel nanoformulated PEG-bpoly(epsilon-caprolactone) micelles of rapamycin. Cancer Chemother Pharmacol. 2008;61(1):133-144.

27. Shuai X, Ai H, Nasongkla N, Kim S, Gao J. Micellar carriers based on block copolymers of poly(epsilon-caprolactone) and poly(ethylene glycol) for doxorubicin delivery. J Control Release. 2004; 98(3):415-426.

28. Talelli M, Rijcken CJ, van NCF, Storm G, Hennink WE. Micelles based on HPMA copolymers. Adv Drug Deliv Rev. 2010;62(2): 231-239.

29. Forrest ML, Yanez JA, Remsberg CM, Ohgami Y, Kwon GS, Davies NM. Paclitaxel prodrugs with sustained release and high solubility in poly(ethylene glycol)-b-poly(epsilon-caprolactone) micelle nanocarriers: pharmacokinetic disposition, tolerability, and cytotoxicity. Pharm Res. 2008;25(1):194-206.

30. Safavy A, Raisch KP, Mantena S, et al. Design and development of water-soluble curcumin conjugates as potential anticancer agents. J Med Chem. 2007;50(24):6284-6288.

31. Kakizawa Y, Kataoka K. Block copolymer micelles for delivery of gene and related compounds. Adv Drug Deliv Rev. 2002;54(2):203-222.

32. Kannaiyan R, Shanmugam MK, Sethi G. Molecular targets of celastrol derived from Thunder of God Vine: potential role in the treatment of inflammatory disorders and cancer. Cancer Lett. 2011;303(1): $9-20$. 
33. Jarpe MB, Widmann C, Knall C, et al. Anti-apoptotic versus proapoptotic signal transduction: checkpoints and stop signs along the road to death. Oncogene. 1998;17(11 Reviews):1475-1482.

34. Choi BH, Kim W, Wang QC, et al. Kinetin riboside preferentially induces apoptosis by modulating Bcl-2 family proteins and caspase- 3 in cancer cells. Cancer Lett. 2008;261(1):37-45.

35. Nehra R, Riggins RB, Shajahan AN, Zwart A, Crawford AC, Clarke R. BCL2 and CASP8 regulation by NF-kappaB differentially affect mitochondrial function and cell fate in antiestrogen-sensitive and -resistant breast cancer cells. FASEB J. 2010;24(6):2040-2055.

36. Brenner D, Mak TW. Mitochondrial cell death effectors. Curr Opin Cell Biol. 2009;21(6):871-877.

37. Robertson JD, Orrenius S. Molecular mechanisms of apoptosis induced by cytotoxic chemicals. Crit Rev Toxicol. 2000;30(5):609-627.
38. Zagurovskaya M, Shareef MM, Das A, et al. EGR-1 forms a complex with YAP-1 and upregulates Bax expression in irradiated prostate carcinoma cells. Oncogene. 2009;28(8):1121-1131.

39. Bernard D, Quatannens B, Vandenbunder B, Abbadie C. Rel/NFkappaB transcription factors protect against tumor necrosis factor (TNF)-related apoptosis-inducing ligand (TRAIL)-induced apoptosis by up-regulating the TRAIL decoy receptor DcR1. J Biol Chem. 2001;276(29):27322-27328.

40. Poulaki V, Mitsiades CS, Joussen AM, Lappas A, Kirchhof B, Mitsiades N. Constitutive nuclear factor-kappaB activity is crucial for human retinoblastoma cell viability. Am J Pathol. 2002;161(6):2229-2240.

41. Qu Y, Zhou F, Dai X, et al. Clinicopathologic significances of nuclear expression of nuclear factor-kappaB transcription factors in retinoblastoma. J Clin Pathol. 2011;64(8):695-700.
International Journal of Nanomedicine

\section{Publish your work in this journal}

The International Journal of Nanomedicine is an international, peerreviewed journal focusing on the application of nanotechnology in diagnostics, therapeutics, and drug delivery systems throughout the biomedical field. This journal is indexed on PubMed Central, MedLine, CAS, SciSearch $\AA$, Current Contents ${ }^{\circledR} /$ Clinical Medicine,

\section{Dovepress}

Journal Citation Reports/Science Edition, EMBase, Scopus and the Elsevier Bibliographic databases. The manuscript management system is completely online and includes a very quick and fair peer-review system, which is all easy to use. Visit http://www.dovepress.com/ testimonials.php to read real quotes from published authors. 